\title{
Virtues, Evidence, and Ad Hominem Arguments
}

\author{
PATRICK BONDY \\ Trent University \\ Department of Philosophy \\ CC G12 \\ Peterborough, ON \\ patrickbondy@trentu.ca
}

\begin{abstract}
Argumentation theorists are beginning to recognize that ad hominem arguments are often legitimate. Virtue argumentation theorists argue that a character trait approach to argument appraisal can explain why ad hominems are legitimate, when they are legitimate. But I argue that we do not need to appeal to virtue argumentation theory to explain the legitimacy of ad hominem arguments; a more straightforward evidentialist approach to argument appraisal is also committed to their legitimacy. I also argue that virtue argumentation theory faces some important problems, and that whereas the virtue-theoretic approach in epistemology is (arguably) well-motivated, that motivation does not carry over to virtue argumentation theory.
\end{abstract}

Resumé: Les théoriciens d'argumentation commencent à reconnaître que les arguments ad hominem sont souvent légitimes. Les théoriciens d'argumentation qui emploient la théorie des vertus soutiennent que l'évaluation des arguments qui repose sur des traits de caractère peut expliquer pourquoi les arguments ad hominem sont légitimes, lorsqu'ils sont légitimes. Mais j'avance qu'il n'est pas nécessaire de faire appel à une telle théorie pour expliquer la légitimité de certains arguments ad hominem; une approche à l'évaluation des arguments fondée sur l'évaluation de la vérité et de l'appui des raisons affirme également leur légitimité. Je soutiens aussi que la théorie d'argumentation fondée sur des vertus fait face à certains problèmes importants, et que, alors que l'approche épistémologique fondée sur une théorie des vertus est (sans doute) bien motivée, la motivation ne porte pas sur la théorie d'argumentation qui repose sur les vertus.

Keywords: ad hominem; argument appraisal; evidentialism; virtue theory

\section{Introduction}

Two ideas in the recent argumentation literature are that ad hominem arguments are often legitimate, and that we can fruitfully approach the reconstruction and evaluation of arguments through a virtue-theoretic lens. Discussions of these ideas have 
gone hand-in-hand, since, if ad hominems are legitimate, then appealing to the intellectual character of arguers gives us a way to explain why that is so; and if ad hominems are not legitimate, then it seems that that undermines the virtue-theoretic approach to argument appraisal from the start.

However, in this paper, I aim to pull these two topics apart. ${ }^{1}$ It is true that if the virtue approach to argument appraisal is to be plausible, it must have a convincing story to tell about arguments of various sorts, including ad hominems, but its treatment of the ad hominem is hardly its central feature, and it should not be the ad hominem that we primarily think of when we think of the virtue-theoretic approach to argument appraisal. Rather, its central feature is its view of argumentative virtues as constitutive of the goodness of arguments.

Sections 2 and 3 of this paper explain the kinds of ad hominem arguments that are generally taken to be legitimate, as well as the virtue-theoretic explanation of their legitimacy. In section 4, I argue that we do not need to appeal to virtue theory to explain the legitimacy of ad hominem arguments. A more standard, evidentialist style of epistemic approach to argument appraisal is also perfectly compatible with the legitimacy of ad hominem arguments - in fact, it requires it. The final section of the paper presents two basic objections to a virtue-theoretic approach to argument appraisal.

\section{Ad hominems and virtue epistemology}

The virtue-theoretic approach to argumentation takes its cue from virtue epistemology. The general idea is that, if we want to adopt an epistemic approach to argument evaluation, and we think that intellectual virtues are important in epistemologysay, if we think that they are necessarily exercised in any given case of knowledge-acquisition - then it will be natural to think that intellectual virtues will be central to the account of argument evaluation. So, in evaluating people's arguments, we need to consider, as far as we are able, the sorts of virtues or vices that people are exemplifying in giving their arguments. Intellectual virtues are traits which involve being disposed to form true

\footnotetext{
${ }^{1}$ Paglieri (2015) also aims to pull apart discussions of virtue argumentation theory and ad hominem arguments, though for a different reason: whereas I argue that virtue argumentation theory doesn't offer a better account of ad hominem arguments than an evidentialist approach does, Paglieri thinks that the discussion of ad hominems is a bit of a red herring for virtue theory in the first place.
}

(C) Patrick Bondy. Informal Logic, Vol. 35, No. 4 (2015), pp. 450—466. 
beliefs reliably in certain sorts of circumstances; so, when we evaluate arguments, on the virtue-theoretic approach, we need, among other things, to consider the intellectual character of the arguer.

One obvious worry for taking the evaluation of an arguer's intellectual character into account in evaluating her arguments, however, is that in so doing, we are engaging in what might seem to be irrelevant ad hominem attacks - we are attacking a person instead of her arguments. Whether ad hominem attacks can ever be relevant to the appraisal of a person's argument is therefore relevant to whether the virtue approach to argumentation is legitimate.

There is a recent trend toward treating many uses of ad hominem arguments as legitimate (e.g. Hitchcock 2007; Woods 2007; Aberdein 2010 and 2014; Battaly 2010). There are of course a variety of argument-types that fall under the general ad hominem category. There is "poisoning the well," which is an attack on a person's standing in a situation, to the effect that the person is not entitled to be listened to. There is the tu quoque, which is the "but you do it too!" reply, where a respondent points out an inconsistency between what an arguer says or advocates, on the one hand, and what she does, on the other. There is the abusive ad hominem, which is the attack on a person's character as a means of discrediting what she says. And there is the Lockean ad hominem, which is the type of argument where one argues to a conclusion using only premises to which one's interlocutor agrees or is otherwise committed.

Lockean ad hominem arguments are (nearly) universally recognized as unproblematic. ${ }^{2}$ Whether the other sorts of ad hominems are legitimate depends crucially on whether the purpose of the ad hominem attack is to undercut a person's argument, or to rebut it. If Mary makes an argument, and Sam gives an ad hominem reply, he might thereby be trying either to establish the strong claim that Mary's premises or her conclusion are false (a rebutting reply), on the one hand, or else the weaker conclusion that he merely ought not to accept Mary's argument for her conclusion (an undercutting reply). If Sam gives a tu quoque argument, for example, intending to undercut Mary's assertion that $p$, by showing that she is committed to not- $p$, it makes sense to think that that can be a legitimate move on

\footnotetext{
${ }^{2}$ See Jason (1984) for dissent on this point. For what it's worth, I don't think Jason's case is convincing.

(C) Patrick Bondy. Informal Logic, Vol. 35, No. 4 (2015), pp. 450-466.
} 
Sam's part, which undercuts the support that $p$ enjoys just by virtue of being asserted by Mary. ${ }^{3}$

A number of defenses of ad hominem attacks in the recent literature have allowed that rebutting ad hominem arguments are generally illegitimate, but that undercutting ad hominem arguments are generally legitimate. Heather Battaly writes, for example, that

There are two sorts of ad hominems that are clearly illegitimate: (a) those that conclude that a speaker's claim is false or that her argument is invalid; and (b) those that conclude that we should dismiss the speaker's claim or argument. In contrast, legitimate ad hominems merely conclude that that we should not believe what a speaker says solely on her say-so. (2010, p.386)

Battaly points out that, given that it is often legitimate to take an arguer's character into account in giving ad hominem replies to his arguments, we need an account of character which underpins this feature of argument assessment, and she argues that virtue epistemology provides the character-trait analysis that we need. In giving her account of epistemic character, Battaly appeals to both the responsibilist and the reliabilist strands of virtue epistemology. Roughly, virtue reliabilists think that knowledge requires the exercise of epistemic virtues for which the agent has no responsibility in any important sense, such as perception, memory, and (basic) reliable inference patterns. Virtue responsibilists, on the other hand, think that knowledge requires more than that: they think that knowledge requires the exercise of ep-

\footnotetext{
${ }^{3}$ To be clear: "undercutting attack on an argument" refers to an attack on an argument, where the attack is undercutting. Such attacks may target an argument's conclusion or its premises. An undercutting attack on a conclusion is one that allows that the premises may be true, but argues that they do not after all support the conclusion in the case at hand. An undercutting attack on the premises of the argument is one which allows that the prima facie reasons we have for believing the premises may be true, but that they do not after all support the premises.

Similarly, "rebutting attack on an argument" may be an attack on a conclusion or on its premises. A rebutting attack on a conclusion is one which allows that the premises may be true, but that there is independent and stronger reasons for thinking that the conclusion is false. Similarly for a rebutting attack on the premises and their supporting reasons.

So: when I describe an attack on an argument as either undercutting or rebutting, I do not mean to claim that the attack is necessarily always either intended to rebut or undercut the conclusion. I only mean that the attack, whatever its target may be, is rebutting or undercutting in character. This is a broader notion of what counts as an undercutting attack than what is presented in Aberdein (2014).
}

(C) Patrick Bondy. Informal Logic, Vol. 35, No. 4 (2015), pp. 450-466. 
istemic virtues for which the agent is at least partly responsible. For example, being open-minded and being disposed to actively seek out evidence are responsibilist virtues. For responsibilists, to have knowledge is to have a true belief that is in some important sense creditable to the agent.

Battaly claims (ibid., p.365) that virtue reliabilists and responsibilists each identify important intellectual skills: some of the virtues which make us excellent thinkers are reliabilist, such as relying on sense-perception, and some of them are responsibilist, such as being open-minded. When a person comes to have a belief as the result of the exercise of either reliabilist or responsibilist virtues, she is more likely to have a true belief than she would be if she had instead formed a belief as the result of the exercise of intellectual vices. So, if it can be shown that a person has come to believe the premises of her argument, or that she is inferring her conclusion from her premises, as the result of intellectual virtues, then we have some reason to think that her premises are true, or that her inference is a good one. On the other hand, if it can be shown that an arguer is employing premises or drawing inferences from her premises as the result of intellectual vices, then we thereby have a reason not to accept her argument, at least not just on the basis of her say-so (ibid., p.384).

Battaly holds that ad hominem attacks are therefore legitimate as attacks both on premises and on premise-conclusion support relations, as long as the ad hominem attack is aimed only at undercutting the force of the argument, rather than at rebutting the argument. Considerations about how a person has arrived at her premises and about how she has inferred her conclusion from her premises - or, failing the availability of such information, considerations about how a person generally arrives at her assertions about such matters - can bear on whether we ought to accept her arguments on the basis of her say-so.

\section{Ad hominems, premises, and premise-conclusion support}

It seems clear that Battaly is correct in arguing that ad hominem attacks can be legitimate when they are directed at undercutting the premises of an argument. When an arguer puts forward an argument, he typically asserts the premises, which implicitly conveys that he has warrant for asserting them. ${ }^{4}$ If we can see

\footnotetext{
${ }^{4}$ I want to remain neutral here about what warrants assertion, so I'm happy to say either that an arguer implicitly conveys that he knows the premises of his

(C) Patrick Bondy. Informal Logic, Vol. 35, No. 4 (2015), pp. 450-466.
} 
that he has no warrant for asserting his premises, then his assertion of his premises does not give us any reason for accepting the conclusion of his argument. So if it can be shown that the arguer has arrived at his premises as the result of intellectual vices, then that undercuts the support that his premises would otherwise enjoy in the argumentative situation.

However, it is not clear that we should accept Battaly's defense of the legitimacy of ad hominem attacks on the strength of premise-conclusion support-relations. An undercutting attack on a premise is one that shows that we, as audiences of an argument, should not accept the premise on the basis of the arguer's say-so. Similarly, an undercutting attack on a premiseconclusion relation would be one that shows that we should not accept that the premises support the conclusion, on the basis of the arguer's say-so.

But in an argumentative situation, it is never, or at least not normally, the case that the audience is asked to accept that the premises support the conclusion just on the basis of the arguer's say-so. To accept an inference from premises to a conclusion just on the basis of the arguer's say-so is not to accept the conclusion as a result of the consideration of the argument; it is, rather, to accept the conclusion as a piece of testimony which the arguer is putting forward. Gary Jason makes this point in response to Christopher Johnson's (2009) virtue-theoretic defense of ad hominem arguments, and in particular, Johnson's claim that it can be legitimate to consider a person's character instead of gathering more evidence in order to evaluate whether the arguer's premises really do support her conclusion: "in cases in which you feel that your time is so limited that more evidencegathering is impractical, you should at least be intellectually honest enough to recognize that in such cases, you are no longer evaluating someone's argument; you are only deciding whether to accept his or her testimony" (Jason 2011, p.105).

Similarly, in their critical response to virtue-argumentation theory, Bowell and Kingsbury (2013, p.26ff) argue that although there are legitimate ad hominems, which undercut premises, there are in fact no legitimate ad hominems that undercut premise-conclusion support-relations, because the strength with which premises support a conclusion is independent of the arguer's say-so. Bowell and Kingsbury do allow that there are cases where the strength with which explicit premises support their conclusions can vary depending on what the audience knows of the arguer, but they go on to argue that in such cases, there are

argument, or that he is justified in believing them, or that he has supporting reasons for them even though he does not believe them himself.

(C) Patrick Bondy. Informal Logic, Vol. 35, No. 4 (2015), pp. 450—466. 
implicit ceteris paribus premises in the argument, and it is the varying justification which the audience has for those implicit premises which accounts for the variation in the support for the conclusion provided by the explicit premises. For example: if $\mathrm{S}$ is an audience member, and $\mathrm{S}$ knows that arguer A delights in tricking people, then S might suspect A of some trickery when A puts forward an inductive argument for some conclusion, when the argument depends on some sort of implicit "otherthings-being-equal" premise. S might be justified in suspecting that $\mathrm{A}$ is hiding some information which bears on the truth of that premise, in which case $\mathrm{S}$ would be justified in not accepting the argument, just on the basis of A's say-so. But cases like this are still only cases where ad hominem considerations undercut the premises of arguments, Bowell and Kingsbury argue, because they undercut the implicit ceteris paribus premise.

\section{Evidentialist epistemology and ad hominem arguments}

So it seems that we should accept the legitimacy of undercutting ad hominem arguments directed against an arguer's premises. The legitimacy of such arguments is a necessary condition for the viability of virtue argumentation theory, and so it is important for virtue theorists to be able to show that such arguments are acceptable. However, the fact that undercutting ad hominem arguments directed against the premises of an argument can be legitimate by no means gives us any reason to accept the virtue-theoretic approach to argumentation theory over other approaches. In particular, a more standard approach to argument appraisal, rooted in evidentialist epistemology, also supports the legitimacy of this kind of ad hominem argument.

I will make three assumptions in characterizing an evidentialist approach to argument appraisal. (1) The central purpose of arguments is to rationally/justifiedly persuade an audience of the truth of a conclusion. ${ }^{5}$ (2) A good argument is one that is capable of fulfilling this purpose. (3) What makes beliefs rational or justified is a matter of the evidential support provided by the reasons upon which it is based.

The first and second assumptions are by no means universally accepted as general constraints on a theory of argument appraisal, but they are at least widely accepted, and they are

\footnotetext{
${ }^{5} \mathrm{I}$ am assuming that conclusions of arguments are always truth-apt. If that assumption is false, the account can be modified to include both acceptance of conclusions as true and as practically obligatory, or optimal, etc.
}

(C) Patrick Bondy. Informal Logic, Vol. 35, No. 4 (2015), pp. 450-466. 
characteristic of epistemic approaches to argumentation. ${ }^{6}$ The third assumption is a matter of serious debate among contemporary epistemologists, but it is the defining thesis of evidentialism in epistemology.

Given an evidentialist approach to argument appraisal of this sort, a good argument must be such that its premises are justified by good evidence, and the premises must themselves provide good evidence for its conclusion. Only if those conditions are met is an argument capable of fulfilling its central purpose. Any considerations that bear on the truth or falsity of the premises is evidence for or against the premises. Now, in ordinary cases, there is a presumption that we are justified in accepting what people assert, just on the basis of their asserting it. This presumption is justified by the fact that people are generally cooperative, and by the fact that we need to rely on others' testimony in order to accomplish just about anything (as well as to acquire language and basic capabilities in the first place). Assertions of propositions, in other words, are defeasible evidence for their truth.

So there is an (evidentialist) presumption that the premises of an argument are acceptable, other things being equal. But when we know, or are justified in believing, that an arguer has arrived at her premises in unreliable ways, the fact that the arguer has asserted the premises does not give us any reason to suppose that the premises are true. ${ }^{8}$ Or, if we do not have specific information about how the arguer arrived at the premises in question, but we know that the arguer is in general very unreliable about such matters, then again, the arguer's assertion of the premises does not give us good reason to accept them. In such cases, we would not be justified, by evidentialist lights, in accepting the premises just on the arguer's say-so, because we have evidence bearing on the truth of the premises: specifically, we have defeating evidence, which undercuts the support that the arguer's assertion of his premises confers upon his premises. And that means that the evidentialist approach to argument appraisal allows legitimate ad hominem undercutting attacks. So

\footnotetext{
${ }^{6}$ See Lumer $(2005 a$; 2005b) for a thorough explanation and defense of the epistemological approach in the theory of argument.

${ }^{7}$ See Conee and Feldman (2004) and the essays and replies in Dougherty, ed. (2011) for elaboration, criticism, and defense of the evidentialist approach in epistemology.

${ }^{8}$ Of course "unreliable" doesn't mean "reliably false," so when we find out that an arguer has arrived at a belief in a premise in an unreliable way, that's not automatically evidence for the falsity of the premise. But it is evidence which defeats the support which the premise has just in virtue of being believed by the arguer.
}

(c) Patrick Bondy. Informal Logic, Vol. 35, No. 4 (2015), pp. 450-466. 
we do not need to appeal to virtue epistemology in order to legitimate undercutting ad hominem arguments.

So far, what I have said is mainly in agreement with Bowell and Kingsbury's critique of the virtue-theoretic approach to the theory of argument. In arguing against that approach, however, Bowell and Kingsbury go on to argue that argument appraisal is context-insensitive. This view of theirs is open to challenge (indeed, I think it is mistaken), and I want to point out that it is not a commitment of the evidentialist approach to argument appraisal.

Bowell and Kingsbury argue against the analogy between knowledge and arguments - which, to the extent that virtuous true belief is what constitutes knowledge, would support the view that argument goodness is constituted by the virtuousness of the arguer-as follows:

Consider someone who puts forward a valid argument with true premises but doesn't see that it is a good argument-someone who, for instance, has learned to recite a valid syllogism, or someone who doesn't understand the premises of her own argument, or someone who mistakenly thinks that the premises of her own argument are false. We would not deny that the argument is a good argument; rather, we would say that the arguer has accidentally put forward a good argument. This contrasts with what we would say in the parallel case regarding knowledge: we would deny that the person who accidentally arrives at a true belief that $p$ knows that $p$.

There is a way to restore the parallel with virtue epistemology: deny that accidentally sound arguments are good arguments... However, this does not fit with the sense of good argument being used here. It would force us to say that if two different arguers presented the same sentences in order to reach the same conclusions in the same way, there are actually two different arguments present. There are rhetorical and dialectical purposes for embracing that conclusion, but not for the purposes at hand. When it comes to argument evaluation, the standard view is standard for a reason. It allows us to say that if one person presents a good argument, another person can use that same argument, confident that it will remain so. Virtue argumentation theorists see the difference but are blind to the sameness. (2013, p.30, authors' emphasis)

I will argue in section 5 that there is an important disanalogy between knowledge and arguments, but I do not think that Bowell and Kingsbury have identified it. Their general characteriza- 
tion of good arguments (ibid., p.23) is in line with assumptions (1) and (2) above, in my characterization of an evidentialist approach to argument appraisal: good arguments, on their view, must give their audiences good, justifying reasons to accept their conclusions. But, given this characterization of good arguments, it should be clear that accidentally sound arguments are not good arguments. For if the participants in an argumentative exchange do not see that the arguer has put forward a sound argument (say, they do not understand the premises), then they are not justified in accepting the conclusion on the basis of the argument. ${ }^{9}$ This idea is not new in the argumentation literature ${ }^{10}$ : soundness is not sufficient for good argument, for soundness is not sufficient for justified belief in the conclusion of an argument. Cases where the participants do not understand the premises of an argument are one type of case where an argument cannot yield justified belief in its conclusion, even if it is a sound argument.

But the rejection of soundness as sufficient for good argument does not entail, as Bowell and Kingsbury seem to think, that the same premises used in the same way to defend the same conclusion will constitute different arguments in different argumentative contexts. All that it entails is that argument goodness is context-sensitive - and that is exactly what we should expect, given the evidentialist approach, because the available evidence will be different in different contexts. So we should not expect that it will always be the case that one person can use an argument that is good in one context, and another person will always be able to use the same argument in another context, confident that it will remain good in the new context.

\section{Problems for virtue argumentation theory}

Bowell and Kingsbury are wrong, then, in thinking that what makes arguments good is context-insensitive, so their argument against the analogy between knowledge and arguments does not succeed. Nevertheless, there are good reasons for rejecting a vir-

\footnotetext{
${ }^{9}$ If an arguer were to accept a conclusion on the basis of a sound argument which she does not see is sound, then her resulting belief in the conclusion will (likely) enjoy propositional but not doxastic justification.

${ }^{10}$ See Hamblin (1970) for some early dissatisfaction with soundness as sufficient for good argument.
}

(C) Patrick Bondy. Informal Logic, Vol. 35, No. 4 (2015), pp. 450-466. 
tue-theoretic construal of good arguments. I will briefly set out two reasons here. ${ }^{11}$

(1) First of all, we should bear in mind that intellectually (or argumentatively) vicious people can sometimes give and accept good arguments, just as virtuous people can give and take in bad arguments. Consider the conception of virtuous arguers as people who are disposed to spread truths around (Aberdein (2010, p.173)). On this conception, it should be clear that good arguers can sometimes give bad arguments. Just as a glass can be disposed to break if dropped onto a hard surface, but it might luckily remain intact if it lands at just such an angle, a person can be disposed to spread truths around, and yet (unluckily) give a bad argument. For example, she might have good reason for thinking that she is employing premises which the audience will be justified in accepting, but which the audience in fact has good grounds for rejecting. In such a case, it is perhaps rational for the arguer to give the argument, but it will not be a good argument, in the sense of being capable of rationally persuading the audience of the truth of its conclusion.

So, insofar as the virtue-theoretic approach holds that argument goodness is constituted by the exercise of argumentative virtues, it does not allow a possibility which we should allow: the possibility of bad arguers giving good arguments, and of good arguers giving bad arguments.

Now, Battaly (2010, section 3) does respond to an analogous problem for virtue epistemology. The problem for virtue epistemology is that it seems that people can acquire knowledge, even if they do not possess the relevant intellectual virtues. For example, a subject might be extremely dogmatic and closedminded in most of his thinking about the natural and social world, but in a fit of research activity sprung by his desire to publish a popular novel, he might nevertheless acquire knowledge that there really never was good evidence for the existence of weapons of mass destruction in Iraq before the invasion which toppled Saddam Hussein's regime. In this case, we cannot make reference to the subject's exercise of the intellectual virtues of open-mindedness and sensitivity to evidence in explaining why he acquired knowledge, in spite of his active search for knowledge about a specific topic, for he does not possess those virtues, and he therefore could not have exercised

${ }^{11}$ A third problem, which we can set aside because it is somewhat controversial, is the general challenge to virtue-theoretic accounts in ethics, that humans do not in fact have the kinds of stable character traits which virtue theorists suppose we have (cf. Harman 1999, Doris 1998).

(C) Patrick Bondy. Informal Logic, Vol. 35, No. 4 (2015), pp. 450-466. 
them. He has acted as an intellectually virtuous person would, but he is not intellectually virtuous himself.

Battaly's way to handle such cases is to allow that people can acquire knowledge, even though they neither possess intellectual virtues nor seek to acquire knowledge for intellectually virtuous motives. All it takes to acquire knowledge, on her account, is that the subject perform an act that an intellectually virtuous person would do in similar circumstances (ibid., p.380).

The analogous move in defense of the virtue-theoretic account of argument appraisal would be to hold that arguers need not possess or exercise their argumentative virtues in order to give good arguments. All that they need to do is what a virtuous arguer would do in similar circumstances.

However, because this reply accepts that good arguments need not result from the exercise of intellectual virtues, there seems to be little reason to maintain that it is the virtues of argument that explain what makes arguments good. The more traditional evidentialist style of explanation of what makes arguments good is much more natural. The evidentialist explanation is that arguments are good when they are capable of yielding justified belief or acceptance of their conclusions - and the features of arguments which make them capable of yielding justified belief in or acceptance of their conclusions do not make essential reference to the features of the argumentative characters of arguers. Rather, the explanation of the virtuous or vicious nature of argumentative character traits should be given in terms of whether certain character traits promote or hinder the practice of engaging in arguments in such a way as to arrive at justified belief or acceptance of conclusions. Virtues of argument are virtues of argument, in other words, because they are conducive to producing and accepting good arguments. But we need an independent account of argument goodness in order to be able to identify what traits count as virtues of argument in the first place.

(2) The second reason for not accepting the construal of argument appraisal in virtue-theoretic terms is that there just isn't any reason to opt for a virtue-theoretic construal of argument goodness over alternatives such as the evidentialist approach. For one thing, the motivation for accepting a virtuetheoretic analysis of knowledge does not straightforwardly carry over to argumentation theory, since there is a relevant disanalogy between knowledge and argument. According to many virtue epistemologists, true belief counts as knowledge when the truth of the belief is creditable to the subject, due to her having arrived at the true belief as a result of the exercise of a cognitive 
virtue (cf. Zagzebski (1996), Sosa (2007), Greco (2003; 2010)). Sosa's metaphor of the archer is a good way to illustrate the idea: an archer's successful shot is creditable to him just in case he hits the target as a result of his exercise of his competence as an archer (rather than, say, as the result of beginner's luck, or of a combination of a trickster's moving the target and a sudden strong gust of wind's moving the arrow to the target's new location). Similarly, knowledge is thought, according to virtue epistemologists, to be a kind of cognitive success due to skill or virtue, in the same way that the archer's shot is a success due to skill.

If this is the correct way to think of knowledge, and if good arguments are supposed to yield knowledge ${ }^{12}$ when the participants in the argumentative exchange form beliefs in their conclusions on the basis of the premises, then that seems to be a good reason to think that the goodness of arguments is intimately bound up with the exercise of intellectual virtues. However, it is easy to see that good arguments need not be such as to be able to yield knowledge of their conclusions. In particular, there can be good arguments for false conclusions, and there can be good arguments for true conclusions in Gettier situations. In such cases, arguments can be good, and they can establish justified belief in their conclusions, even though they are incapable of establishing knowledge of their conclusions.

When we are talking about knowledge, cognitive virtues seem to be important because knowledge is necessarily nonaccidentally true belief, and because it is plausible to think that a subject's having a true belief is not accidental, when her belief is held as a result of a cognitive virtue. However, it is not the case that good arguments must necessarily have non-accidentally true conclusions. The reason for appealing to the cognitive virtues in the account of knowledge is therefore absent when it comes to giving an account of good argument.

So there's no straightforward transfer of the motivation for virtue theory in epistemology over to argumentation theory. However, there is a second, and perhaps more important, reason people have opted for a virtue-theoretic construal of argument goodness. The reason is that, if we think that what makes arguments good is that they are cogent, in the sense that they satisfy the RSA criteria (relevance, sufficiency, acceptability), then we will be faced with the kind of serious intuitive counterexamples which Paglieri (2015) calls "bogent" (bad but cogent) arguments. Paglieri borrows two examples from Cohen (2013),

\footnotetext{
${ }^{12}$ As Battaly 2010, pp.362-363, seems to suggest they should.
} 
where Cohen is voicing some deep dissatisfaction with the notion that cogency is sufficient for good argument. One example is the old and tired "Socrates" argument:

P1. Socrates is a man

$\mathrm{P} 2$. All men are mortal

C. So, Socrates is mortal

It's easy to see why Cohen is exasperated with arguments like the Socrates argument: the conclusion isn't likely ever to be in doubt; and no one would be likely to give such an argument, if the conclusion were in doubt; and if someone were to give such an argument if the conclusion were in doubt, no one would ever be persuaded by it. And yet, the argument seems like one with acceptable premises, which are relevant to and apparently sufficient for establishing the conclusion. So, Cohen thinks, cogency (understood as RSA) isn't sufficient for good arguments.

But there are two observations to make which undermine the idea that these "bogent" arguments give us any reason to reject a cogency-approach to argument evaluation in favour of an agent — or virtue-based approach. First, not everyone accepts the RSA criteria for cogency. For example, Crispin Wright thinks that a cogent argument is one "whereby someone could be moved to a rational conviction of the truth of its conclusion" (2000, p.140). Wright thinks that it must be possible to acquire warrant for believing the conclusion of a cogent argument, perhaps for the first time, from one's warrant for believing the premises. And it's not clear (to me at least) that it's possible to acquire a warrant for believing the conclusion of the Socrates argument from its premises; perhaps you need to already be warranted in believing that Socrates is mortal, in order to be warranted in believing that all men are mortal. If that's right, then the premises of the Socrates argument do not transmit their warrant to the conclusion, and so the argument isn't cogent after all, in spite of the fact that it's sound.

On the other hand, suppose that it is possible to be warranted in believing the premises in the Socrates argument without having a prior warrant for believing the conclusion. In that case, it does seem possible to acquire a warrant for believing its conclusion on the basis of its premises, and it no longer seems like an intuitively bad argument after all.

The second response to Cohen's worry is that it's not even clear that the RSA criteria really do countenance the Socrates argument after all. For if any subject $\mathrm{S}$ were ever to doubt the conclusion of the argument-if anyone were ever to doubt that 
Socrates is mortal - then, because of the obvious support which that proposition enjoys (as embodied in the Socrates argument), then surely $\mathrm{S}$ would have some reason for doubting at least one of the premises of the Socrates argument, which would render that premise unacceptable. So it's just not clear that we should agree with Cohen and Paglieri in thinking that we need to move away from traditional approaches to explaining what makes arguments good, in favour of virtue-based accounts.

For these reasons - the explanatory backwardness of the virtue approach to argument appraisal, and the fact that there just isn't any positive reason to accept the virtue-theoretic approach-I do not think that the virtue-theoretic approach can provide the theoretical underpinning for a general account of argument. But, having said that, I want to acknowledge that employing virtues of argument in our accounts can nevertheless be useful, especially in teaching critical thinking and introductory argument theory, even though the virtues will not be basic elements in our accounts. Open-mindedness, for example, is a plausible candidate for a virtue of argument. What makes it a virtue is the fact that people with open minds are better situated to be able to fairly consider arguments against their own views; when the arguments against their views are strong ones, they will be able to change their beliefs to fit with what their new evidence bases support. Teaching people to be open-minded is therefore good for the purpose of teaching people to be good producers and consumers of arguments. More generally, teaching people to be virtuous arguers is good, even though the virtues are not constitutive of what makes arguments good.

\section{Acknowledgments}

I would like to thank the Social Sciences and Humanities Research Council of Canada for their support for this research, in the form of a Postdoctoral Fellowship, award number 756-20130261. I would also like to thank two Informal Logic referees for their valuable feedback on a previous draft.

\section{References}

Aberdein, Andrew. (2010). Virtue in Argument. Argumentation. vol. 24, pp. 165-179. (2014). In Defence of Virtue: The Legitimacy of Agent-Based Argument Appraisal. Informal Logic. vol.34, no. 1 , pp. 77-93. 
Battaly, Heather. (2010). Attacking Character: Ad Hominem Argument and Virtue Epistemology. Informal Logic. vol. 30, no. 4, pp. 361-390.

Bowell, Tracy, and Kingsbury, Justine. (2013). Virtue and Argument: Taking Character into Account. Informal Logic. vol. 33, no. 1, pp. 22-32.

Cohen, Daniel. (2013). Virtue, in Context. Informal Logic. vol. 33, no. 4, pp. 471-485.

Conee, Earl, and Richard Feldman. (2004). Evidentialism: Essays in Epistemology. Oxford: Oxford University Press.

Doris, John. (1998). Persons, Situations, and Virtue Ethics. Nous. vol. 34, no. 4, pp. 504-530.

Dougherty, Trent, ed. (2011). Evidentialism and its Discontents. Oxford: Oxford University Press. pp. 226-232.

Greco, John. (2003). Knowledge as Credit for True Belief. in Michael DePaul and Linda Zagzebski, eds. Intellectual Virtue. Oxford: Oxford University Press, pp. 111-134. (2010). Achieving Knowledge: A Virtue-Theoretic Account of Epistemic Normativity. Cambridge: Cambridge University Press.

Hamblin, C. L. (1970). Fallacies. Newport News, VA: Vale Press.

Harman, Gilbert. (1999). Moral Philosophy Meets Moral Psychology: Virtue Ethics and the Fundamental Attribution Error. Proceedings of the Aristotelian Society. New Series. vol. 99, pp. 315-331.

Hitchcock, David. (2007). Is there an Argumentatum Ad Hominem Fallacy? in Hans Hansen and Robert Pinto, eds. Reason Reclaimed. Newport News, VA: Vale Press, pp. 187-199.

Jason, Gary. (1984). Is there a Case for Ad Hominem Arguments? Australasian Journal of Philosophy. vol. 62, no. 2, pp. 182-185.

Jason, Gary. (2011). Does Virtue Epistemology Provide a Better Account of the Ad Hominem Argument? A Reply to Christopher Johnson. Philosophy. vol. 86, pp. 95-119.

Johnson, Christopher. Reconsidering the Ad Hominem. Philosophy. vol. 84, pp. 251-266.

Lumer, Christoph. (2005a). Introduction: The Epistemological Approach to Argumentation-A Map. Informal Logic. vol. 25, no. 3, pp. 189-212. (2005b). The Epistemological Theory of Argument-How and Why? Informal Logic. vol. 25, no. 3, pp. 213-243.

Paglieri, Fabio. (2015). Bogency and Goodacies: On Argument Quality in Virtue Argumentation Theory. Informal Logic. vol. 35, no. 1, pp. 65-87. 
Sosa, Ernest. (2007). A Virtue Epistemology: Apt Belief and Reflective Knowledge, Volume I. Oxford: Clarendon Press.

Woods, John. (2007). Lightening up on the Ad Hominem. Informal Logic. vol. 27, no. 1, pp. 109-134.

Wright, Crispin. (2000). Cogency and Question-Begging: Some Reflections on McKinsey's Paradox and Putnam's Proof. Philosophical Issues, vol. 10: Skepticism. pp. 140-163.

Zagzebski, Linda. (1996). Virtues of the Mind. Cambridge: Cambridge University Press. 